\title{
A COMPREHENSIVE AND FLEXIBLE MULTIPLE REGRESSION PROGRAM FOR ELECTRONIC COMPUTING
}

\author{
A. KOZAK ${ }^{1}$ AND J. H. G. SMITH ${ }^{2}$
}

\section{$A B S T R A C T$}

Since 1957 multiple regression programs used by the U.B.C. Faculty of Forestry have been revised several times to increase their flexibility and encourage comprehensive analyses. The program described here accepts either basic data or results of earlier analyses, simplifies review of variables, allows supplementary analysis of specified variables, and ensures that the most important ones can be thoroughly evaluated. In a few minutes, using this program, an I.B.M. 7040 computer can reduce thousands of observations to the summaries needed for effective study of many forestry problems.

\section{INTRODUCTION}

Many forestry problems can be studied most effectively by use of regression and correlation analyses. Multiple regression techniques make it possible to determine the most potent independent variables for estimation of a dependent variable. Often, they also can result in effective mathematical models of important biological and economic relationships. Many useful examples of regression techniques in forestry and forest research have been reported. (Freese 1964, Jeffers 1963, Kozak 1963, Lawrence 1965, Eis 1965, Smith 1959, and Smith et al. 1961). Multiple regression analyses will become even more important as availability of digital computers increases.

The purpose of the present paper $^{3}$ is to describe a comprehensive and flexible computer program which has evolved during eight years of use of electronic computers for multiple regression analyses of many forestry problems at UBC. Other programs of interest to foresters have been listed by Munro, Kozak and Hejjas (1965).

\section{History of THE Program}

The program was first written in machine language for an ALWAC IIIE Computer by Drs. T. Hull and C. Froese in 1957. This program handled one dependent and 31 independent variables.

In 1961, the program was re-written in FORTRAN IA by Dr. Froese for an IBM 1620, without any modification of the mathematical principles. This program handled 20 variables, and allowed more than one dependent variable to be analysed.

\footnotetext{
${ }^{2}$ Assistant Professor, University of British Columbia, Faculty of Forestry, formerly, Research Officer, Canada Department of Forestry, Forest Products Research Branch, Vancouver Laboratory.

"Professor, University of British Columbia, Faculty of Forestry.

Reviews by Drs. R. W. Wellwood and A. L. Wilson are much appreciated.
} 
The FORTRAN IA Program was modified to FORTRAN II by Dr. Froese in 1962. Some modification of the mathematical principles was introduced in 1964, and soon after (when the University of British Columbia installed an IBM 7040, July, 1964), the program was changed to FORTRAN IV language by Kozak (1964).

In principle, the program was further modified by the authors of this paper in 1965, and this is the form which will be discussed herein.

\section{Mathematical Principles of the Program}

The most important problem in interpreting linear multiple regression is that of determining the relative importance rather than simple statisical significance of independent variables. With the exception of this problem, the mathematical principles of the technique are exact (Ezekial and Fox 1959, Freese 1965, Furnival 1964, Grosenbaugh 1958, Schultz and Goggans 1961, Steel and Torrie 1960, and Williams 1959).

The selection of the most significant subset of independent variables from those originally available has not been satisfactorily resolved theoretically. According to Miller (1965), the selection of the independent variables is a technical, rather than a statistical problem. In most cases the investigator must use some experience and judgment to determine which, and how many, independent variables should be included in the final equation.

There are three general procedures for finding the "best set" of independent variables. First, one can compute all possible combinations of the independent variables. This method is highly desirable, but the computing time can become excessive with a large number of variables. Because $2^{40}-1$ regressions can be formed from 40 independent variables, their calculation would require an astronomical amount of time on any computer (Furnival, 1964). Second, one can build up equations commencing with one independent variable and adding others which are effective in the presence of those already in the equation. The third method commences with an equation of all variables and then eliminates them one at a time. Because use of all variables accounts for the maximum portion of variance, this method is preferred by most foresters. Either of the second or third procedures with 40 independent variables can be followed in a very few minutes on computers like the IBM 7040.

The program described in this paper uses the third method, often called the elimination method, in combination with the first method. It eliminates the variables one by one from the total model. Then it selects the three independent variables which have the highest simple correlation coefficient with the dependent variable and calculates equations for all the possible combination of equations of this set.

In the UBC program, until recently, the variable eliminated from the equation was the one which made the most negative or least positive contribution to the total variance attributable to the independent variables. The idea was based on the following formula: 


$$
\begin{aligned}
& \mathrm{SS}_{\text {Regression }}=b_{1} \operatorname{SPX}_{1} \mathrm{Y}+\mathrm{b}_{2} \operatorname{SPX}_{2} \mathrm{Y}+\ldots .+\mathrm{b}_{\mathrm{n}} \operatorname{SPX}_{\mathrm{n}} \mathrm{Y} \\
& \text { Where: } \\
& \text { SS }_{\text {Regression }}=\text { Net sum of squares attributable to the independent variables. } \\
& \mathbf{b}_{1} \\
& \text { SPXiY } \\
& =\text { Regression coefficient for the } i^{\text {th }} \text { independent variable. } \\
& =\text { Net sum of products of the dependent }(Y) \text { and } i^{\text {th }} \\
& \text { independent }(X) \text { variables. }
\end{aligned}
$$

From formula 1, it seems logical to eliminate the variable which forms the most negative or least positive (if there is no negative) product. In other words eliminate the variable which most decreases or least increases the sum of squares attributable to the independent variables. However, Kozak (1964) showed that elimination by this criterion might remove significant variables at the beginning of the process. Because the existing program often eliminated important variables that were negatively correlated with highly significant independent variables, the procedure was modified in 1964. This modified method was based on formula 1 again, but eliminated each time the variable with the smallest absolute contribution to variance accounted for by the regression equation. Since, when using this method, there is no assurance that the most important variable will be retained in the equation at the end of the process, another modification was introduced. This procedure is based on the calculation of the variance ratio of the contribution of each independent variable included in the model. The $t$ statistic can also be used since $t=\sqrt{ } F$ with one and $n$ degrees of freedom for $F$ and $n$ degrees of freedom for t. The variable with the smallest variance ratio is eliminated first. The formula for the variance ratio is:

$$
F_{1}=\frac{b_{1}^{2}}{S_{b 1}^{2}}
$$

Where:

$F_{1}=$ variance ratio for $i^{\text {th }}$ independent variable and $S_{b i}=$ standard deviation of the $i^{\text {th }}$ regression coefficient.

This method has the advantage over the other two that a test of significance can be carried out at any stage of the elimination, and when the variance ratio becomes significant, the elimination can be stopped. Since this method again does not ensure ending with the most important variable, Miller's (1965) t-prime criterion was incorporated into our program in 1965. Miller's t-prime criterion goes a long way toward correcting for the commonly observed situation that in many forestry problems there seldom is true independence among dependent and independent variables. Miller's t-prime criterion involves application of a weighting factor to supplement the use of partial coefficients of determination for selection of variables to be eliminated.

This new criterion corrects our t-statistics to account for inflation of regression coefficient due to high correlations among the independent variables. The formula for t-prime is:

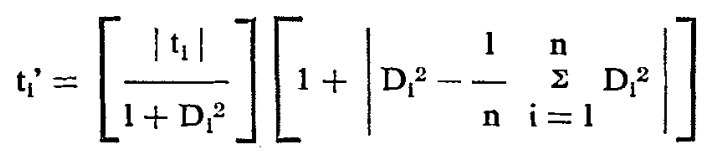




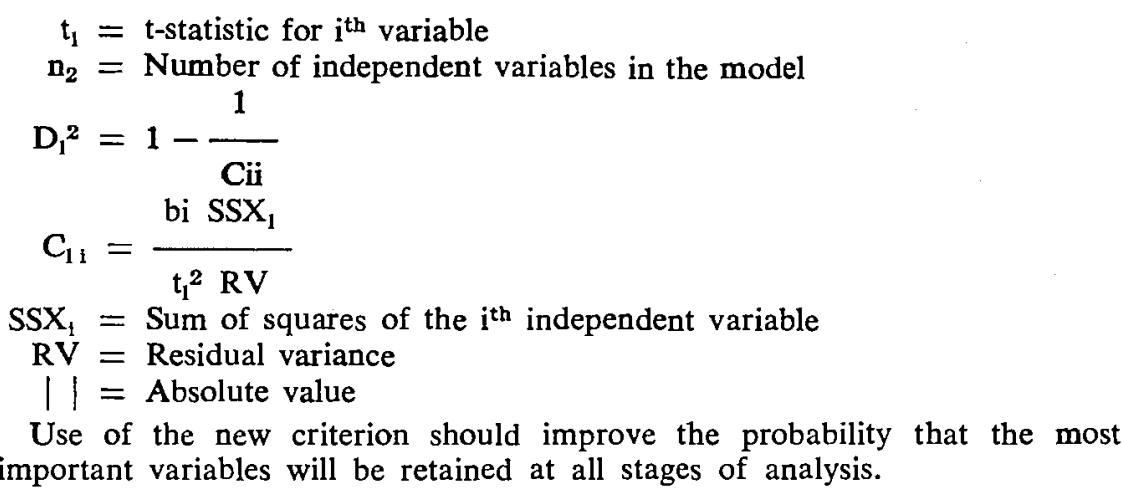

\section{General Description of the Program}

The present program is written in FORTRAN IV for an IBM 7040 DATA PROCESSING SYSTEM with a core storage capacity of 32,768 words. The system is installed with IBM 1042 Card Read-Punch, IBM 1403 Printer, IBM 729 Magnetic Tape Units and IBM 1301 Disk Storage. With the exception of compiling, the program uses only the Card Read-Punch and the Printer units. However, this can easily be modified as required.

The program can be operated in five major versions. That to be used must be defined by control cards. The five versions are:

1. The program accepts the information in two forms. The input includes either the original observations of the dependent and independent variables, or the mean values, covariance matrix and number of observations of the variables. Use of the matrices makes it easier to store data and reanalyse earlier studies.

2. The statistics and matrices can be obtained in both printed and punched forms or in printed form only. The punched cards will facilitate subsequent analyses if needed.

3. The computation can be stopped after the calculation of means, standard deviations, and covariance and correlation matrices. This version is very useful as a substitute for, or supplement to, graphical analysis for "screening" the variables.

4. Several subsets of the most economical, or interesting, or important original variables can be defined by control cards, and for each subset the parameters of the multiple regression equation are calculated. If required, elimination of the independent variables from any given subset can be performed. For a subset, the process of eliminating a variable and performing a regression analysis with the remaining variables is repeated until one independent variable is left. To assist in interpretation of results, the code name of the variable that has been eliminated at each stage is printed. Each subset can be controlled individually as to whether or not the elimination of the variables will be done after the multiple regression equation is calculated. 
5. A control card defines whether or not the regression analysis is required for all possible combinations of the three independent variables which have the largest simple correlation coefficients (regardless of sign) with the dependent variable of a given subset.

Combination of the various versions are possible.

The program consists of the main line program and two subroutines. A description of its use and a listing of the program are available.

The program accepts up to 60 variables (including transformed and calculated variables). Any of these 60 variables can be selected as the dependent variable. If desired, regression equations can be obtained for more than one dependent variable in the same analysis.

For each set of original observations and transformed or calculated data, the following results are calculated and printed:

1. Title of the analysis

2. Number of observations

3. Means

4. Maximum and minimum values of the variables

5. Covariance matrix

6. Standard deviations

7. Simple correlation coefficient matrix

The means and covariance matrix can be punched as well. If a rerun is desirable, a considerable amount of computing time can be saved by using these intermediate results.

As previously discussed various regression analyses can be performed on a set of data. For each regression analysis, the following information is printed:

8. The code name of the variables in the subset for regression analysis

9. Regression coefficients

10. Standard deviation of the regression coefficients

11. Intercept

12. Residual variance

13. Standard error of estimate

14. Multiple coefficient of determination $\left(\mathrm{R}^{2}\right)$

15. Multiple correlation coefficient (R)

16. An "F" value for the multiple regression, with the appropriate degrees of freedom

When the elimination version is used, two additional items are printed:

17. An "F" value for each independent variable

18. The code name of the variable to be eliminated

When eliminations or all possible combination versions are computed, results from " 8 " to " 18 " are printed for every regression equation.

\section{Computing Time}

Because many versions are possible, it is difficult to give an exact formula for the amount of time required for computing. The main factors affecting it are:

1. The number of variables

2. The number of observations (if original data are read)

3. The number and complexity of transformations and calculations used. 
4. The number of subsets to be calculated

5. Whether or not the elimination version is used

6. Whether or not the all-combinations version is used

Generally speaking, most multiple regression problems in forestry and forest research can be solved in from one to ten minutes on an IBM 7040 machine.

\section{CONCLUSION}

Use of appropriate versions of this program can improve the quality and reduce the costs of many multiple regression analyses. By providing a framework for considering importance as well as significance of variables the program also can help the investigator use his experience and judgment in evaluating his data.

\section{Literature Cited}

BROWN, D. M. and L. NG-YELIM. 1963. Least squares linear regression analysis for 1 dependent and up to 24 independent variables. Canada Department of Forestry, Program Library for IBM 1620 Computer. File No. 06-01-001 B.

EIS, S. 1962. Statistical analysis of severinl methods for estimation of forest habits and tree growth near Vancouver, B.C. The University of British Columbia, Fac. of For., Forestry Bulletin No. 4. 76 pp.

EZEKIAL, M. and K. A. FOX. 1959. Methods of correlation and regression analysis: linear and curvilinear. New York: Wiley \& Sons. 548 pp.

FREESE, F. 1964. Linear regression methods for forest research. U.S. Forest Serv. Res. Paper FPL $17.136 \mathrm{pp}$.

FURNIVAL, G. M. 1964. More on the elusive formula of best fit. Proceedings, Socicty of American Foresters, Denver, Colorado. $201-207$.

GROSENBAUGH, L. R. 1958. The clusive formula for best fit: a comprchensive new machine program. U.S. Forest Serv., Southern Forese Expt. Sta. Paper No. 158, 9 pp.

JEFFERS, J. N. R. and T. M. BLACK, 1963. An analysis of variability in Pinns contorta. Forestry, 36 (2): $199-218$.

KOZAK, A. 1963. Analysis of some factors associated with distribution and intensity of attack by cone and seen insects in Douglas fir. University of British Columbia, Fac. of For. Thesis for the Ph.D. degree. $179 \mathrm{pp}$.

KOZAK, A. 1964. Problems in multiple regression analysis. Paper presented at the Biometric Sociery Meeting, Vancouver, B.C. 6 pp.

LAWRENCE, P. R. 1965. A regression niodel-building computer program. Commonwealth of Australia. Dept. of National Development, Forestry and Timber Bureau. Bulletin No. 40, $38 \mathrm{pp}$.

McCRACKEN, D. D. 1957. Digital Computer programming. Wiley \& Sons, Inc., New York. $253 \mathrm{pp}$.

MiLleR, F. A. 1965. Strengthening stepwise regression. Paper presented at the Meeting of Association for Computing Machinery, Paln Beach, Florida. 22 pp.

MUNRO, D. D., A. KOZAK and J. HEJJAS. 1965. Applications of electronic computing to forestry and forest resenrch at the University of British Columbia: Prcpared for the mecting of the Advisory Group of Forest Staristicians (I.U.F.R.O.), Stockholm, Sweden, 8 pp.

SCHULTZ, E. F. and T. F. GOGGANS, 1961. A systematic procedure for determining potent independent variables in multiple regression and discriminant analysis. Agricultural Experiment Station. Auburn University. Bullerin 336. 75 pp.

SMITH, J. H. G. 1959. Comprehensive and economical designs for studies of spacing and thinning. Forest Science, 5 (3): $237-245$.

SMITH, J. H. G., J. KER and J. CSIZMAZIA. 1961, Econonics of reforestation of Douglas fir, western henlock and western red cedar in the Vancouver forest district. The University of British Columbia, Fac. of For. Forestry Bulletin No. 3. $144 \mathrm{pp}$.

STEEL, G. D. and J. H. TORRIE. 1960. Principles and procedures of statistics. McGraw-Hill Book Company, Inc., New York. 481 pp.

WTLLIAMS, E., Jr. 1959. Regression analysis. Wiley \& Sons, New York. 214 pp. 